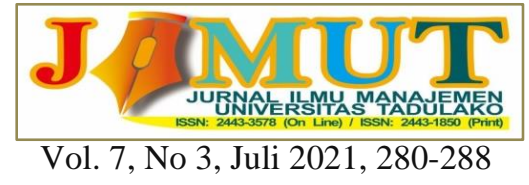

\title{
PENGARUH KEYAKINAN DIRI DAN DUKUNGAN SOSIAL TERHADAP MOTIVASI KERJA KARYAWAN PADA PT. SARANAMUKTI PUTERASEJATI KOTA PALU
}

\author{
Anggun Yudita \\ Niluh Putu Evvy Rossanty \\ Program Studi S1 Jurusan Manajemen Fakultas Ekonomi dan Bisnis, Universitas Tadulako \\ Email: anggunyidta@gmail.com;npe.rossanty@gmail.com
}

\begin{abstract}
The purpose of this study was to determine the effect of self-confidence and social support on employee work motivation at PT Saranamukti Puterasejati Palu City, by having 37 respondents. Sampling uses total sampling which is where the number of samples is equal to the population. The analytical model used is multiple linear regression. The results of this study indicate that (1) Based on the findings of the study indicate that the effect of self-confidence and social support simultaneously affect employee work motivation at PT. Saranamukti Puterasejati of Palu has a Fcount value (5.739)> Ftable value (3.28). (2) self-confidence (XI) does not have a significant effect on employee work motivation at PT Saranamukti Puterasejati Palu. And (3) social support (X2) has a significant effect on employee work motivation at PT Saranamukti Puterasejati Palu.
\end{abstract}

Keywords: Self Confidence, Support, Work Motivation

Abstrak

Tujuan dari penelitian ialah untuk mengetahui pengaruh keyakinan diri dan dukungan sosial terhadap motivasi kerja karyawan pada PT Saranamukti Puterasejati Kota Palu, dengan memiliki 37 responden. Pengambilan sampel menggunakan total sampling yaitu dimana jumlah sampel sama dengan populasi. Model analisis yang digunakan adalah regresi linear berganda.Hasil penelitian ini menunjukkan bahwa (1) Berdasarkan hasil temuan penelitian menunjukkan bahwa pengaruh keyakinan diri dan dukungan sosial secara serempak mempengaruhi motivasi kerja karyawan pada PT. Saranamukti Puterasejati kota Palu memiliki nilai $F_{\text {hitung }}$ (5.739)> nilai $F_{\text {tabel }}$ (3.28). (2) keyakinan diri (X1) berpengaruh tidak signifikan terhadap motivasi kerja karyawa pada PT Saranamukti Puterasejati kota Palu. Dan (3) Dukungan sosial (X2) berpengaruh signifikan terhadap motivasi kerja karyawan pada PT Saranamukti Puterasejati kota Palu.

Kata kunci: Keyakinan Diri, Dukungan, Motivasi Kerja

\section{PENDAHULUAN}

Motivasi kerja merupakan faktor terpenting dalam perkembangan sebuah organisasi. Tindakan ini muncul dari para pelaku organisasi baik dari level terbawah hingga pada level tertinggi. Motivasi yang dimiliki oleh setiap individu tersebut tentunya akan mendorong mereka untuk bekerja dengan lebih baik yang tidak hanya ditunjukkan secara pribadi namun mampu bekerja secara kelompok dalam sebuah organisasi.

Mewujudkan motivasi kerja bisa dilakukan dengan cara mengoptimalkan tenaga, pikiran dan perasaan diri dalam bekerja. Jika setiap individu telah memiliki motivasi dengan baik, maka kemampuan berupa tenaga yang dikeluarkan, kemampuan berupa pikiran untuk menganalisa pekerjaan dan ketenangan perasaan saat bekerja tentunya akan bisa berjalan dengan mudah. Intinya ialah semua berasal dari motivasi diri dalam bekerja. Menurut Hasibuan (2003:95) dimana motivasi kerja merupakan pemberian daya penggerak yang dapat mewujudkan semangat kerja individu agar mereka dapat bekerja sama, bekerja efektif dan terintegrasi dengan segala daya upayanya untuk mencapai kepuasan.

Karyawan yang memiliki motivasi kerja tentunya tidak terjadi dengan sendirinya, melainkan dipengaruhi oleh beberapa faktor, seperti pada faktor keyakinan diri. Motivasi kerja bisa menurun 


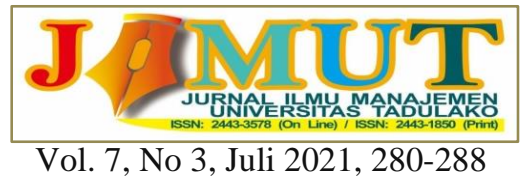

dengan drastis apabila keyakinan diri yang dimiliki oleh pekerja atau karyawan sangat minim dan bahkan tidak ada sama sekali. Hal ini tentunya akan berpengaruh pada cara kerja dan tujuan organisasi yang dicapai. Oleh karena itu, dalam melaksanakan pekerjaan, seluruh anggota organisasi/perusahaan harus bisa memiliki keyakinan diri. Baron dan Byrne (1991) keyakinan diri yang tinggi akan membawa individu pada prestasi yang lebih baik dalam berbagai bidang karena itu akan membawa perubahan psikologi yang mengurangi rasa sakit dan lebih dapat mentolerir stress.

Dukungan sosial merupakan bentuk penyampaian pesan yang positif ataupun strategi memberikan benda/barang yang membuat para pekerja menjadi lebih termotivasi dalam melaksanakan pekerjaan yang selanjutnya. Khususnya pekerjaan yang berkaitan dengan infrastruktur jalan, misalnya yang dilakukan oleh PT. Saranamukti Puterasejati Kota Palu pada jalur daerah Kebun Kopi, Desa Nupabomba, Kabupaten Donggala.

Permasalahan yang terdapat di PT. Saranamukti Puterasejati yaitu menurunnya motivasi kerja karyawan sehingga menghambat proses kerja dalam perbaikan infrastruktur jalan seperti yang terjadi pada jalur Kebun Kopi, desa Nupa Bomba Kabupaten Donggala. Hingga saat ini, perbaikan jalur Kebun Kopi belum selesai, proses pengerjaan masih terus dilakukan namun memakan waktu yang cukup lama. Alhasil pengguna jalan harus rela menggunakan waktu yang cukup lama saat menuju ke tempat tujuan.

Penyebab lainnya ialah pengguna jalan tidak nyaman dalam melakukan mobilisasi dikarenakan pada saat hujan tiba, jalan menjadi licin disebabkan banyaknya lumpur dari gusuran alat berat, sedangkan pada waktu siang, pengguna jalan harus rela mendapatkan debu jalanan yang begitu banyak sehingga mengganggu konsentrasi dalam bekerja. Masalah yang dialami tersebut tentunya harus bisah diselesaikan dengan baik, salah satu contohnya ialah dengan memaksimalkan pekerjaan infrastruktur yang bisah dimulai dari motivasi kerja karyawan.

\section{KAJIAN LITERATURE}

\section{Keyakinan Diri}

Konsep dasar teori self-efficacy merupakan kepercayaan bahwa pada setiap individu telah memiliki kemampuan mengontrol pikiran, perasaan, dan perilakunya sehingga apa yang mereka lakukan dapat terkontrol dengan baik. Self-efficacy adalah masalah persepsi subyektif artinya selfefficacy tidak selalu memperlihatkan tenaga sebenarnya, tetapi terkait dengan keyakinan yang dimiliki individu (Bandura, 1997: 41). Keyakinan diri juga Menurut Pervin \& John (dalam Bandura, 1997) seseorang yang memiliki self-efficacy yang tinggi akan sangat termotivasi dalam mencapai tujuannya. Semakin tinggi tingkat self-efficacy seseorang maka tingkat motivasinya akan semakin tinggi pula.

\section{Dimensi Keyakinan Diri}

Bandura (1997) membagiself-efficacy ke dalam tiga dimensi, yaitu level, generality, dan strength.

a. Dimensi level merupakan dimensi yang memiliki taraf kesulitan yang tinggi bagi individu yang akan mampu mengatasinya. Individu yang memiliki self-efficacy yang tinggi akan memiliki keyakinan tentang kemampuan untuk melakukan suatu tugasnya. Sebaliknya individu yang memiliki self-efficacy rendah akan memiliki keyakinan yang rendah pula tentang setiap usaha yang dilakukan.

b. Dimensi generality yaitu variasi situasi dimana seseorang yang merasa yakin terhadap kemampuannya. Dengan semakin banyak self-efficacy diterapkan pada berbagai kondisi, maka semakin tinggi self-efficacy seseorang.

c. Dimensi strength ini berkaitan dengan kekuatan self-efficacy seseorang saat bertatapan dengan tuntutan kerja atau permasalahan. Semakin kuat self-efficacy dan semakin besar ketekunan, maka semakin tinggi kemungkinan kegiatan yang dipilih dan dilakukan berhasil. 


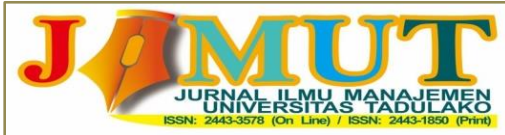 \\ Vol. 7, No 3, Juli 2021, 280-288}

\section{Dukungan Sosial}

Rook (1985, dalam Smet, 1994) menjelaskan bahwa dukungan sosial menjadi salah satu fungsi pertalian sosial dengan melihatkan tingkat dan kualitas umum dari hubungan interpersonal yang akan menjaga seseorang dari masalah stres. Dukungan sosial membuatindividu tenang, diperhatikan, timbul rasa percaya diri dan kompeten. Tersedianya dukungan sosial akan membuat individu merasa dicintai, dihargai dan menjadi bagian dari kelompok. Lanjut dukungan sosial menurut House \& Khan (dalam Apollo \& Cahyadi, 2012: 261) merupakan luapan emosi yang bersifat membantu, memberikan infirmasi, bantuan instrument, dan memberikan nilai positif terhadap seseorang dalam menyikapi masalahnya.

\section{Dimensi Dukungan Sosial}

House (Smet, 1994) mengemukakan ada empat jenis atau dimensi dukungan sosial yaitu:

a. Dukungan emosional yang berarti memiliki dukungan yang mencakup ungkapan empati, kepedulian dan perhatian kepada seseorang yang bersangkutan.

b. Dukungan penghargaan adalah dukungan yang melewati ungkapan hormat yang positif kepada seseorang, dorongan maju merupakan gagasan atau perasaan seseorang yang dapat perbandingan positif seseorang dengan orang lain.

c. Dukungan instrumental merupakan dukungan yang mencakup bantuan langsung dalam bentuk bantuan keuangan atau bantuan praktis.

d. Dukungan informatif merupakan dukungan yang mencakup pemberian nasehat, petunjuk-petunjuk dan umpan balik.

\section{Motivasi Kerja}

Motivasi merupakan tenaga yang mendorong sehingga mengakibatkan anggota organisasi ingin hingga rela untuk menggerakan tenaganya dalam bentuk kemampuan atau keterampilan kerjanya dan dapat bertanggung jawab terhadap kegiatan yang telah di buat dan melakukan kewajibannya, dalam pencapaian tujuan dan berbagai sasaran organisasi yang telah ditentukan sebelumnya (Siagian, 2003). Motivasi adalah hasrat seseorang yang menyebabkan orang tersebut melakukan tindakannya (Mathis dan Jackson, 2006).

\section{Foktor Motivasi Kerja}

Penelitian ini menggunakan teori dua faktor dari Frederick Herzberg yang mengatakan bahwa seseorang terdorong untuk melakukan pekerjaan karena dua faktor yaitu faktor yang membuat seseorang merasakan tidak puas akan hasil yang dia terima (dissatisfiers) dan faktor yang membuat individu puas (satisfiers). Menurut hasil penelitian yang dilakukan Herzberg ada dua faktor yang mendorong atau memotivasi orang untuk bekerja, yaitu:

1. Faktor Motivator

Faktor motivator disebut juga dengan kondisi instrinsik, adalah kondisi dimana individu merasakan bahwa mereka puas akan motivasi yang mereka dapatkan dalam menghasilkan kinerjanya. Jika kondisi ini tidak ada, maka kondisi ini ternyata tidak maka seseorang akan merasakan ketidak puasaan dalam bekerja. (Manullang, 1981:151) menyatakan bahwa faktor-faktor motivator meliputi :
a. Achievement (keberhasilan pelaksanaan)
b. Recognition (pengakuan)
c. The work it self (pekerjaan itu sendiri)
d. Responsibilities (tanggung jawab)
e. Advancement (pengembangan)

Motivasi internal adalah motivasi yang dibangkitkan dari dirinya sendiri, dimana tenaga kerja dapat bekerja karena tertarik dan senang dengan pekerjaan yang memberikan makna, kepuasan dan kebahagiaan pada dirinya. Motivasi internal disebut juga faktor motivator. 


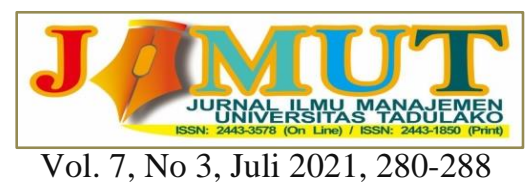

2. Faktor Hygiene

Faktor hygiene disebut juga dengan kondisi ekstrinsik, ialah dimana kondisi pekerjaan yang kurang baik dan menimbulkan rasa ketidak puasan dalam bekerja. Jika kondisi itu ada maka hal tersebut tidak memotivasi karyawan. Kondisi tersebut adalah faktor-faktor yang membuat individu merasa tidak puas (dissatisfiers), karena faktor-faktor tersebut diperlukan untuk mempertahankan hirarki yang paling rendah, yaitu tingkat tidak adanya kepuasan (non-dissatisfiers).

Menurut M. Manullang (1981:151) menyatakan faktor hygienemeliputi :

a. Police and administration (kebijakan dan administrasi)

b. Technical supervisior (supervise perusahaan)

c. Interpersonal supervisor (hubungan antar pribadi)

d. Working condition (kondisi kerja)

e. Wages (gaji/upah)

Faktor hygiene, pada dasarnya adalah hubungan kerja dengan lingkungan kerja dimana karyawan bekerja, sehingga apabila faktor ini diabaikan atau dibiarkan tidak sehat, maka akan menimbulkan ketidak puasan para karyawan. Motivasi eksternal adalah motivasi yang berasal dari luar yang berupa peraturan dan kebijaksanaan perusahaan. Motivasi ekternal disebut faktor hygiene.

\section{Kerangka Pikir}

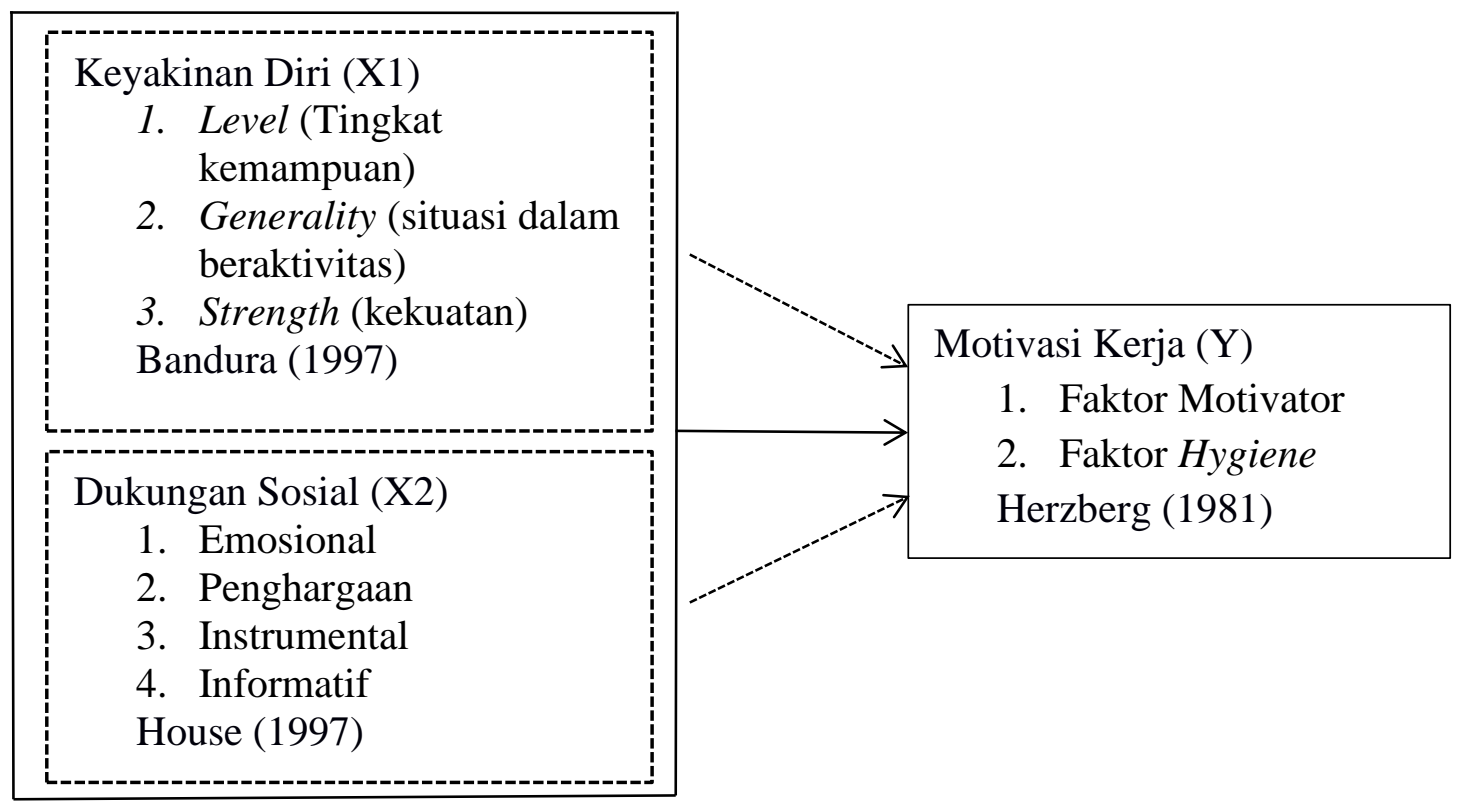

Gambar 1 Analisa pengaruh simultan dan parsial terhadap motivasi kerja

\section{METODE PENELITIAN}

Jenis penelitian menggunakan penelitian kuantitatif dengan pendekatan menggunakan penelitian deskriptif. Riset ini akan mengungkapkan tentang "Pengaruh keyakinan diri dan dukungan sosial terhadap motivasi kerja karywan pada PT Saranamukti Puterasejati kota Palu". Dengan mengambilObjek pada keyakinan diri dan dukungan sosial karyawan dalam bekerja di PT Saranamukti Puterasejati kota Palu. Subjek dari penelitian iniialah karyawan PT Saranamukti Puterasejati kota Palu.

Teknik pengambilan sampel dalam penelitian ini secara total sampling. Total sampling merupakan teknik pengambilan sampel dimana jumlah sampel sama dengan populasi (Sugiyono, 2007). Sampel pada penelitian ini adalah semua jumlah populasi menjadi sampel. yaitu 37 responden yang akan digunkan untuk mendapatkan hasil penelitian. 


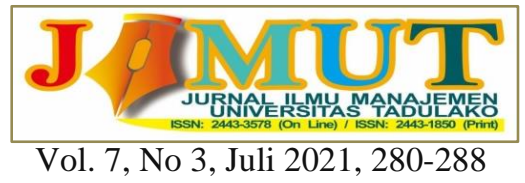

Uji validitas menurut Sugiyono (2016:177) memperlihatkan nilai derajat kecepatan69 antara data yang sebenearnya terjadi pada objek, data yang dikumpulkan dalam mencari validitas sebuah item, kita mengkorelasikan skor item dengan total item-item yang ada. Jika koefisien antara item dengan total item sama atau diatas 0,3 maka item tersebut dinyatakan valid, tetapi jika nilai korelasinya dibawah 0,3 maka item terebut dinyatakan tidak valid.

Uji reliabilitas digunakan agar dapat mengetahui hasil ukur jauh apabila tetap konsisten dalam melakukan uji dua kali atau lebih dalam pengukur. Untuk melihat reliabilitas masing-masing instrument yang digunakan, penulis menggunakan koefisien cronbach alpha $(\alpha)$ dengan menggunakan program SPSS (Statistical Program Sience and Social). Suatu instrumen dikatakan reliabel jika nilai cronbach alpha $(\alpha)$ lebih besar dari 0,6 .

Uji normalitas melakukan penelitian agar dapat menguji apakah dalam model regresi variable yang mengganggu memliki hasil normal, seperti hasil dari uji $\mathrm{T}$ dan $\mathrm{F}$ memberikan hasil bahwa nilai residual mengikuti distribusi yang normal. Kalau uji ini telah di langgar maka nilai yang kita cari menjadi tidak valid. Dua cara agar kita mengetahui apakah residual distribusi normal atau tidak dengan analisi grafik dan uji statistik. Residual berdistribusi normal jika memiliki nilai signifikansi $>0,05$ (Ghozali, 2011: 160-165).

Menurut Ghozali (2011: 105-106) uji multikolinieritas bertujuan untuk melihat apakah ada korelasi anatar variable bebas, dengan cara melihat jika nilai VIF $<10$, maka dapat disimpulkan data bebas dari gejala multikolinieritas.

Uji heterokedastisitas bertujuan agar mengetahui adakah ketidaksamaan variance dan residual satu penglihatan ke penglihatan lain. Untuk mengetahuinya kita menggunakan uji grafik plot, uji park, uji qlejer, uji white, pengujian ini menggunakan grafik plot dengan nilai dependen ZPRED dengan residualnya SRESID. Tidak terjadi heteroskedastisitas apabila tidak ada pola yang jelas, serta titik-titik menyebar di atas dan di bawah angka 0 pada sumbu Y. (Ghozali, 2011: 139-143).

Uji statistik t ini adalah untuk menguji keberhasilan koefisien regresi secara parsial. Pengujian ini dilakukan untuk mengetahui apakah variabel bebas (X) secara tunggal berpengaruh terhadap variabel terikat $(\mathrm{Y})$ untuk membandingan variable bebas dengan derajat kesalahan 5\% $(\alpha=0.05)$. Apabila nilai $t_{\text {hitung }} \geq t_{\text {tabel }}$, meberikan pengaruh yang bermakna kepada variabel terikat. Uji $t$ ini menggunakan derajat kebebasan $\mathrm{df}=\mathrm{n}-\mathrm{k}-1$ dimana $\mathrm{n}=$ banyak observasi dan $\mathrm{k}=$ jumlah regresor.

Uji statistik $\mathrm{F}$ bertujuan untuk mengetahui pengaruh secara simultan atau bersama-sama antar variabel independen terhadap variabel dependen. Pengaruh tersebut memiliki tingkat signifikansi pada alpha 5\%. Adapun metode untuk menentukan apabila nilai signifikan $<0,05$ dan $F_{\text {hitung }}>F_{\text {tabel. }}$.

Uji determinasi $\left(\mathrm{R}^{2}\right)$ mengukur seberapa jauh variable-variabel independen . nilai koefisiennya yaitu nol dan satu. Nilai $\mathrm{R}^{2}$ kecil berarti nilai kemampuan variable independen. Nilai yang mendekati variable-variabel independen memberikan semua informasi yang dibutuhkan (Ghozali, 2013: 46).

Dalam menjawab permasalahan serta hipotesis yang diajukan digunakan alat analisis statistik, yaitu regresi berganda.Adapun penggunaan regresi berganda yang memilikipermasalahan dan hipotesis dengan mengajukan hasil penelitian variabel independen $(\mathrm{X})$ terhadap dependen $(\mathrm{Y})$ melalui bentuan SPSS 23. Dengan bentuk persamaan rumus regresi linear berganda menurut sugiyono (2010:277) sebagai berikut:

$\mathrm{Y}=\mathrm{b}_{0}+\mathrm{b}_{1} \mathrm{X}_{1}+\mathrm{b}_{2} \mathrm{X}_{2}+\ldots . .+\mathrm{b}_{\mathrm{n}} \mathrm{X}_{\mathrm{n}}$

Dimana:

$\mathrm{Y} \quad=$ Variabel Terikat (dependent variable)

$\mathrm{a}=$ Konstanta (intercept)

$\mathrm{X}_{1}-\mathrm{Xn}=$ Variabel Bebas (independent variable) 


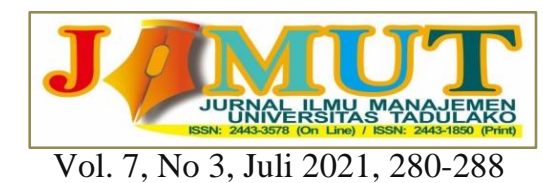

$\mathrm{b}_{1}-\mathrm{b}_{2}=$ Besaran yang digunakan (koefisien regresi)

e $\quad=$ Kesalahan Pengganggu

Bila diformulasikan matematis Regresi Linear Berganda yang diaplikasikan dalam penelitian ini, maka akan diperoleh bentuk persamaan sebagai berikut:

$\mathrm{Y}=\mathrm{a}+\mathrm{b}_{1} \mathrm{X}_{1}+\mathrm{b}_{2} \mathrm{X}_{2}$

Dimana:

$\mathrm{a}=$ Konstanta

$\mathrm{Y}=$ Motivasi kerja

$\mathrm{X}_{1} \quad=$ Keyakinan diri

$\mathrm{X}_{2} \quad=$ Dukungan sosial

$\mathrm{b}_{1}-\mathrm{b}_{2}=$ Parameter yang diukur

\section{HASIL DAN PEMBAHASAN}

Dalam menjawab hasil dari uji hipotesis dalam penelitian ini menggunakan alat analisis statistik regresi linear berganda dengan menggunakan softwer SPSS versi 23. Untuk lebih jelasnya dapat dilihat pada tabel 2:

Tabel 2

Hasil Uji Regresi

\begin{tabular}{|c|c|c|c|c|c|}
\hline \multirow[t]{2}{*}{ Model } & \multicolumn{2}{|c|}{$\begin{array}{l}\text { Unstandardized } \\
\text { Coefficients }\end{array}$} & \multirow{2}{*}{$\begin{array}{l}\text { Standardized } \\
\text { Coefficients } \\
\text { Beta }\end{array}$} & \multirow[t]{2}{*}{$T$} & \multirow[t]{2}{*}{ Sig. } \\
\hline & $\mathrm{B}$ & Std. Error & & & \\
\hline (Constant) & 1.333 & .844 & & 1.579 & .124 \\
\hline Keyakinan_Diri & -.358 & .317 & -.318 & -1.128 & .267 \\
\hline Dukungan_Sosial & .959 & .363 & .745 & 2.638 & .012 \\
\hline R Square & 0.252 & & & & \\
\hline F Hitung & 5.739 & & & & \\
\hline$\alpha$ & 0.05 & & & & \\
\hline
\end{tabular}

Sumber : hasil data penelitian

Dari hasil uji regresi pada Tabel 2. Dapat diketahui bahwa persamaan regresi adalah : Y $=1.333$ $0.358\left(\mathrm{X}_{1}\right)+0.959\left(\mathrm{X}_{2}\right)$ Berdasarkan persamaan regresi liner berganda diatas, dapat dijelaskan nilai koefisien keyakinan diri dan dukungan sosial sebagai berikut:

1. Nilai konstanta sebesar 1.333 yang memberikan nilai positif artinya bahwa variabel independen (keyakinan diri dan dukungan sosial) dalam penelitian memiliki pengaruh positif terhadap motivasi kerja pada PT. Saranamukti Puterasejati di Kota Palu. Rasio keyakinan diri dan dukungan sosial tidak ada atau nol rasio keputusan karyawan masi sebesar $1.333 \%$.

2. Nilai koefisien variabel keyakinan diri $\left(\mathrm{X}_{1}\right)$ sebesar -0.358. dapat diartikan bahwa variabel keyakinan diri mengalami penurunan, sebesar -0.358 atau $-35.8 \%$ yang diasumsikan variabel independen lain tetap.

3. Nilai koefisien variabel dukungan sosial $\left(\mathrm{X}_{2}\right)$ sebesar 0.959 dapat diartikan bahwa variabel dukungan sosial mengalami penaikan, sebesar 0.959 atau $95.9 \%$ yang diasumsikan variabel independen lain tetap.

Untuk mengetahui pengaruh signifikan secara parsial ataupun simultan dari variabel independen ke dependen dengan menggunakan analisis uji t dan uji f yaitu menghasilkan:(1) uji $F$ di peroleh

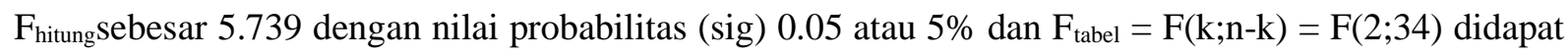
nilai $F_{\text {tabel }}=3.28$ karena nilai $F_{\text {hitung }}(5.739)>$ nilai $F_{\text {tabel }}$ (3.28) maka dapat disimpulkan bahwa kedua variabel independen berpengaruh signifikan memberikan konstribusi yang besar terhadap variabel 


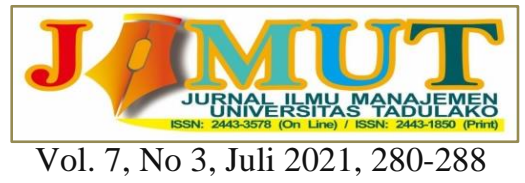

motivasi kerja karyawan. (2) uji $\mathrm{T}$ dengan varibel keyakinan diri (X1) memiliki nilai p-value $0.267>0.05$ artinya tidak signifikan. Sedangkan $t_{\text {hitung }}<t_{\text {tabel }}(-1.128<2.35)$. Sehingga dapat disimpulkan bahwa koefisien keyakinan diri secara parsial berpengaruh tidak signifikan terhadap motivasi kerja karyawan PT. Saranamukti Puterasejati kota Palu dan (3) varibel dukungan sosial (X2) memiliki nilai p-value $0.012<0.05$ artinya signifikan. Sedangkan $t_{\text {hitung }}>t_{\text {tabel }}(2.638>2.35)$. Sehingga dapat disimpulkan bahwa koefisien dukungan sosial secara parsial berpengaruh signifikan terhadap motivasi kerja karyawan PT Saranamukti Puterasejati kota Palu.

Berdasarkan hasil penelitian uji simultan (uji F) dapat dilihat bahwa variabel keyakinan diri dan dukungan sosial berpengaruh secara simultan terhadap motivasi kerja karyawan pada perusahaan PT. Saranamukti Puterasejati Kota Palu.Ini membuktikan bahwa berdasarkan realita yang terjadi di perusahaan tersebut, karyawan-karyawannya mampu menerapkan dengan baik konsep keyakinan diri dan dukungan sosial sehingga bisa berpengaruh terhadap motivasi kerja mereka. Apabila motivasi kerja telah baik tentunya tujuan yang akan hendak dicapai oleh perusahaan di bidang infrastruktur jalan tentunya bisa terwujud dengan sangat baik pula

Berdasarkan konsepnya bahwa penerapan kepercayaan diri yang dilakukan oleh karyawan perusahaan PT. Saranamukti Puterasejati Kota Palu pada dasarnya diterapkan dengan sangat baik.Mereka meyakinkan dengan baik dirinya untuk bisa bekerja secara maksimal baik demi organisasi dan demi kebutuhan diri. Menurut Baron danByrne (2004: 187) mengemukakan bahwa, "self-efficacyadalah penilaian seseorang yang memiliki kemampuan ataukompetensinya untuk melakukansuatu tugas, mencapai suatu tujuan, danmenghasilkan sesuatu". Di pihak lain, Santrock (2009) menyatakan bahwa, "self-efficacymerupakan keyakinan bahwa saya bisa".

Selanjutnya untuk bisa meningkatkan motivasi kerja bagi setiap karyawan di perusahaan PT. Saranamukti Puterasejati Kota Palu, mereka juga menerapkan dukungan sosial. Menurut Effendi dan Tjahyono (dalam Alsa, 2006) menyatakan bahwa dukungan sosial merupakan transaksi interpersonal yang suda diajukan untuk memberikan bantuan kepada orang lain dan bantuan itu diperoleh dariorang yang berartibagi individu yang menyangkut. Dukungan sosial sangat berperan penting untuk menjaga keadaan psikologiindividu yang mengalamitekanan. Melalui dukungan sosial, kenyamanan psikologis akan semakin tinggi karena adanya perhatian dan pengertian yang memunculkan perasaan memiliki, meningkatkanharga diri serta memiliki perasaanpositif mengenai diri sendiri.

Dengan hasil uji hipotesis secara parsial (uji t) diperoleh hasil dari pengaruh keyakinan diri berpengaruh tidak signifikan terhadap motivasi kerja karyawan pada PT. Saranamukti Puterasejati Kota Palu dimana t hitung lebih kecil dari t tabel.Dilihat dari penelitian Aziz (2014)yang menunjukan bahwa keyakinan diri berpengaruh positif terhadap motivasi kerja karyawan pada Balai Besar Veteriner Wates Yogyakarta. Sedangkan menurunnya keyakinan diri karyawan PT. Saranamukti Puterasejari kota Palu disebabkan oleh terjadinya kejadian alam, yang menghambat kinerja perusahaan dengan menargetkan suatu pekerjaan harus terselesaikan pada bulan dan tahun yang sudah disepakati, tapi pada faktanya karyawan PT. Saranamukti Puterasejati Kota Palu masih melaksanakan infrastruktur di jalan transulawesi Desa Nupa Bomba yang sampai sekarang belum terselesaikan.

Dimana hasil uji hipotesis secara parsial (uji t) diperoleh hasil dari pengaruh dukungan sosial berpengaruh signifikan terhadap motivasi kerja karyawan pada PT Saranamukti Puterasejati kota Palu. Dimana $t$ hitung lebih besar dari t tabel yang artinya bahwa pengaruh dukungan sosial menjadi salah satu variabel yang mempengaruhi motivasi kerja pada PT. Saranamukti Puterasejati Kota Palu.Hal ini menunjukkan bahwa dukungan sosial sangat baik buat motivasi kerja karyawan.

Dari kedua variabel tersebut dukungan sosial sangat mempengaruhi motivasi kerja karyawan dimana $t$ hitung lebih besar dari $t$ tabelnya sedangkan keyakinan diri memiliki $t$ hitung yeng lebih kecil dati $\mathrm{t}$ tabelnya.Berdasarkan hasil hitungan tersebut, dibuktikan bahwa dukungan sosial bisa 


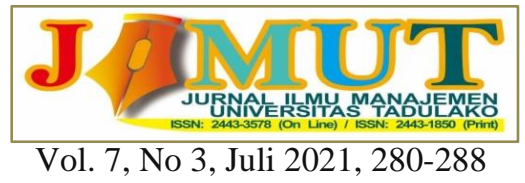

mempengaruhi motivasi kerja karyawan di PT Saranamukti Puterasejati Kota Palu.Dukungan sosial merupakan salah satu bentuk penyampaian pesan yang mampu mempengaruhi psikologi setiap orang untuk menjadi lebih baik. Dalam penelitian ini, kita dapat melihat penelitian dari Bakhri (2011) yang dimana dukungan sosial mempunyai pengaruh positif terhadap motivasi berprestasi karyawan, dukungan sosial sangat diperlukan oleh siapa saja, dalam bentuk motivasi kerja ataupun motivasi berprestasi, Rook dalam Smet (1994) mengatakan bahwa dukungan sosial merupakan salah satu fungsi dari ikatan sosial, yang dimana individu merasa dicintai, diperhatikan, dihargai, dan menjadi bagian dalam kelompok. Oleh karena itu, karyawan yang bekerja disuatu perusahaan perlu mendapatkan dukungan baik dari pimpinan ataupun rekan kerja di lingkungan kerja mereka.

Untuk bisa mencapai tujuan dengan maksimal, maka setiap perusahaan tentunya berharap motivasi kerja dari seluruh karyawan dapat terjaga dan meningkat dengan baik.Hal inilah yang dilakukan oleh karyawan di PT. Saranamukti Puterasejati Kota Palu.Mereka tetap menjaga dan meningkatkan motivasi kerja di perusahaan tersebut.

\section{KESIMPULAN DAN SARAN}

\section{Kesimpulan}

Berdsarkan hasil dan pembahan penelitian yang mengangkat judul Pengaruh Keyakinan Diri dan Dukungan Sosial Terhadap Motivasi Kerja Karyawan Pada PT. Saranamukti Puterasejati Kota Palu, dapat disimpulkan sebagai berikut :

1. Keyakinan diri dan dukungan sosial secara serempak mempengaruhi motivasi kerja karyawan pada PT. Saranamukti Puterasejati Kota Palu. Semakin tinggi keyakinan diri dan dukungan sosial karyawan maka semakin baik dan tinggi juga motivasi kerja karyawan.

2. Berdasarkan hasil penelitian untuk variabel keyakinan diri berpengaruh tidak signifikan terhadap motivasi kerja karyawa pada PT. Saranamukti Puterasejati Kota Palu.

3. Berdasarkan hasil penelitian untuk variabel dukungan sosial berpengaruh signifikan terhadap motivasi kerja karyawan pada PT. Saranamukti Puterasejati Kota Palu.

\section{Saran}

Berdasarkan uraian hasil penelitian dan kesimpulan, maka ada beberapa hal yang perlu direkomendasikan kepada pihak-pihak yang terkait dalam penelitian ini sebagai berikut :

1. Dalam meningkatkan pengaruh keyakinan diri karyawan pada PT. Saranamukti Puterasejati Kota Palu, sebaiknya PT. Saranamukti Puterasejati Kota Palu lebih memperhatikan apa saja yang dapat meningkatkan keyakinan diri karyawan terhadap apa yang mereka kerjakan untuk dapat meningkatkan motivasi kerja karyawan. Dengan memperhatikan tugas, pokok dan fungsi (Tupoksi) yang jelas tentang detail yang relevan dengan masing-masing karyawan, agar karyawan yakin dengan apa yang akan mereka kerjakan.

2. Untuk menjaga peningkatan dukungan sosial terhadap motivasi kerja, karyawan harus dapat menjaga emosional, saling mengharagai, saling membantu dan saling memberikan saran agar dukungan sosial dapat lebih terjaga sehingga dapat meningkatkan motivasi kerja karyawan. Hal tersebut akan berguna sehingga karyawan berhasil menyelesaikan pekerjaan mereka yang sulit.

3. Untuk peneliti selanjutnya, diharapkan dapat menggunakan data yang lebih banyak dan akurat agar bisa mendapatkan hasil yang memuaskan, dan mencoba faktor lain untuk mengetahui pengaruh motivasi kerja karyawan di PT. Saranamukti Puterasejati Kota Palu.

\section{REFERENSI}


Apollo \& Andi Cahyadi. 2012. Konflik Peran Ganda Perempuan Menikah yang Bekerja Ditinjau dari Dukungan Sosial Keluarga dan Penyesuaian Diri. Madiun : Program Studi Psikologi, Fakultas Psikologi, Universitas Katolik Widya Mandala Madiun.

Bandura, A. (1997). SELF-EFFICACY: The Exercise of Control. New York: W. H Freeman and Company.

Baron, R. A., \& Byrne, 1991. Sosial Psychology: Understanding Human Interaction, $6^{\text {th }}$ Edition.USA: Allyn \& Bacon.

Ghozali, Imam. 2005, Uji Normalitas Regresi Dengan SPSS. Semarang: Universitas Ponegoro.

Hasibuan, 2003. Organisasi dan Motivasi. Dasar Peningkatan Produktivitas. Jakarta: Bumi Aksara.

Hasibuan, MalayuSP. 1990. Manajemen Sumber Daya Manusia dan Kunci Keberhasilan, Penerbit Haji Masagung, jakarta, 1990.

Manullang, M. 1981. Dasar-dasar Manajemen. Jakarta : Ghalia Indonesia.

Mathis, Robert L. dan John H. Jackson. 2006. Human Resource Management (Manajemen Sumber Daya Manusia). Edisi 10. Jakarta: Salemba Empat.

Qomarudin Aziz, (2014). Pengaruh Keyakinan Diri dan Pengembangan Karyawan Terhadap Motivasi Kerja Karyawan Pada Balai Besar Veteriner (BBVET) Wates Yogyakarta. Fakultas Ekonomi, Universitas Negeri Yogyakarta.

Saifuk Bakhri, (2011). Pengaruh Dukungan Sosial dan Religiusitas Tehadap Motivasi Berprestasi Karyawan Kogas strategic Alliance. Fakultas Psikologi, Universitas Islam Syarif Hidayatullah Jakarta.

Santrock, J. W. (2009). Psikologi Pendidikan. Jakarta: Salemba Humanika

Smet, Bart. (1994). Psikologi Kesehatan. Jakarta: PT. Gramedia Widiasarana Indonesia.

Sugiyono, 2016.Metode Penelitian Kuantitaif, Kualitatif dan R\&D, Bandung : PT Alfabet. 